\title{
The Role of Trust and Team Culture in Knowledge Sharing and OCBs among Government Officials
}

\author{
Thi-Thanh-Thuy Nguyen*', Thi-Thanh-Hien Phan, Thuy-Ai-Phuong Tran \\ Faculty of Economics \\ Ho Chi Minh City University of Technology and Education \\ Ho Chi Minh City, Vietnam \\ *Corresponding author's email: thuynguyen [AT] hcmute.edu.vn
}

\begin{abstract}
To date, numerous empirical studies have been confirmed the key roles of knowledge sharing and organizational citizenship behaviors (OCBs) toward organizational performance. Thus, this study attempts to investigate determinants of knowledge sharing, and OCBs in government officials, which can improve organizational performance based on voluntary behaviors. Given this purpose of the study, the data collected from a sample of 250 government officials from An Nhon village, Binh Dinh Province, Vietnam. This research adopts a cross-sectional study design and utilizes partial least square - structural equation modeling (PLS-SEM) technique through Smart-PLS software. The findings indicate that trust and team culture are determinants that positively and directly influences knowledge sharing and OCBs. This research contributes to the knowledge sharing and OCBs literature, and provides practical implications for public sectors. Managers should generate practices that help organizations enhance trust and team culture among officials, which lead to higher knowledge sharing and OCBs.
\end{abstract}

Keywords--- trust, team culture, knowledge sharing, OCBs.

\section{INTRODUCTION}

Government officers play an important role in connecting relationships as well as transferring information between government and citizens [1]. Officer attitudes usually affect efficiency of information transfer, which are concerned by many scholars in organizational behavior. Volunteer behaviors (e.g., knowledge sharing, organizational citizenship behavior) are required from government officials to gain performance productivity in public sectors [2].

The role of trust in promoting volunteer behaviors has received considerable attention recently [3,4]. Previous scholars have identified a significant impact of trust on knowledge sharing behaviors [5], organizational citizenship behaviors OCBs [6], employee voluntary performance [7]. Current stream of organizational studies recognize trust as a strong enabler of knowledge sharing which further improve team mutual understanding and problem solving experiences [4]. Also, in the context of social exchange, trust plays a key role in enhancing OCBs [8].

Moreover, numerous researches found effect of individuals' personal values on volunteer behaviors [9]. Team members in high pleasure of helping others are available for voluntarily sharing their knowledge and supporting colleagues [10]. Thus, team culture (e.g. enjoy helping) as an element of one's values affects employee's knowledge sharing behaviors [11] and OCBs [12].

Although previous research assess the correlation among trust, team culture, knowledge sharing, and OCBs (e.g., [4, 12, 13]), the empirical findings for public organizational context are still limited. With the growth of internet, government officials easily access to information through various means of communications [14, 15]. However, internet environment also contains many risks and challenges for knowledge sharing and OCBs due to information safety [16]. Whether increasing trust and team culture may lead to higher level of knowledge sharing and OCBs among government officials? This research therefore attempts to bridge this gap, and extends the cope of similar studies through conducting in Vietnam - one of the most dynamic countries in ASEAN.

\section{THEORETICAL FRAMEWORK AND HYPOTHESES DEVELOPMENT}

\subsection{Trust, Knowledge Sharing, and OCBs}

Trust has been defined as "the level of confidence that one individual has in another to act in a fair, ethical, predictable manner" [17, p.165]. In a group context, trust refers to the level of confidence of team members to one another [18]. Trust 
are constructed into two types: emotional and cognitive trust [19, 20]. The emotional content of trust involves a positive affect of self-trust as well as other-trust, whereas the cognitive content of trust concerns "a good rational reasons" for the object of trust $[20,21]$. Two components of trust influence the trust process, and generate the strong relationship between trustor and object of trust.

Hu et al. [22] describe knowledge sharing is behaviors involving transferring or popularize knowledge from one individual to another. The process of knowledge sharing depends on effectiveness of communication among team members, which can lead to higher team performance [23]. Trust amongst group members may improve effective communication within team [4]. Even face-to-face or virtual environment, trust encourages employees to be pleasure to open themselves to each other and transfer knowledge [4, 13]. Trust with two components facilitates knowledge sharing process: (1) confidence on one's willingness to share (emotional); (2) believe in one's competence to transfer (cognitive) [5]. Thus, trust plays a key determinant in leading knowledge sharing amongst team members.

OCBs refer to employee's extra-role behaviors that are discretionary, not directly rewared or punished by formal reward system [24, 25, 26]. Podsakoff et al. [25] provided a multi-dimensional scale of OCBs. The seven dimensions are: (1) Helping Behavior, (2) Sportsmanship, (3) Organizational Loyalty, (4) Organizational Compliance, (5) Individual Initiative, (6) Civic Virtue, and (7) Self Development. These behaviors can target to organizations (OCB-O), colleagues (OCB-I), or customers (OCB-C) [27]. Based on Social Exchange Theory, OCBs are regards as a type of reciprocity of positive social exchanges inside organization (e.g., [27, 28]. When employees trust in organizational management system and coworkers, they are willing to engage in OCBs; then they can get reciprocally a positive feedbacks and "trusted" feeling from organization and colleagues [27, 29]. Thus, trust is one of essential foundation for social relations and enhance OCBs.

Therefore, I propose that:

H1: Trust can positively influence knowledge sharing.

$\mathrm{H} 2$ : Trust can positively influence OCBs

\subsection{Team Culture, Knowledge Sharing, and OCBs}

Culture is defined as "the shared values, beliefs and practices of the people in the organization" [30, p. 77; 31]. Official team in an organization is garthered by cultural diversity of members [32]. According to Hu et al. [33], team culture consists of a set of rules, work expectations, cognition, and actions that team members develop, share and perform. A strong team culture with shared expectations and beliefs can facilitate member and team performance and communication that lead to an effective team [32].

Team culture can influence to when and how employees share knowledge within organization [34]. Asian economies with a collectivist orientation does play an important role in developing team culture [35]. Collectivism culture encourge socialization among team members [36] that lead to development of trust, corporation, and friendly environment which enhance knowledge sharing and OCBs [34, 36, 37]. Knowledge sharing is more popular in organization with knowledge sharing-culture: members share ideas and insights naturally, not forced to do so [30]. Moreover, collective team members engage more in interpersonal helping and extra-role behaviors (i.e. OCBs) due to avoiding team criticism [36, 38].

Therefore, I propose that:

H3: Team culture can positively influence knowledge sharing.

H4: Team culture positively influence OCBs

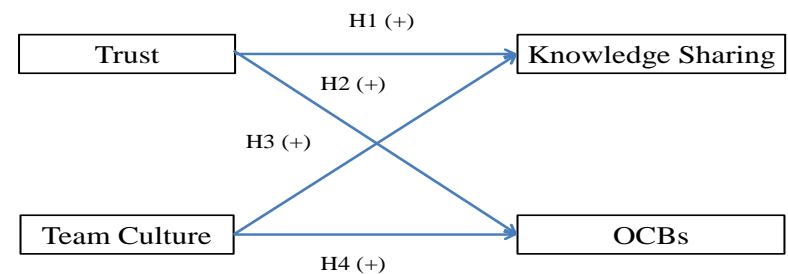

Fig 1. Theoretical Framework 


\section{METHODOLOGY}

\subsection{Sample and Procedure}

Questionaire data were collected of 250 government officials at An Nhon village, Binh Dinh Province, Vietnam. In 2020, Public Administration Reform Index of Binh Dinh, which was announced by the Ministry of Home Affairs, increased by 15 ranks compared to 2019. Thus, government officials in Binh Dinh may strongly emphasize on reforming administration procedure, sharing knowledge, and helping each other in extra- and intra-role tasks.

The survey questionnaire was sent directly to all departments at An Nhon village with cover letter which could explain research purpose and objective. After receiving approval of department leaders, survey questionnaires, which were sent to 310 officials, were collected by head of department. Total 250 responses were returned and found to be valid for the purpose of data analysis (response rate of 80.6\%). Gender distribution of 250 participants explains 59 per cent (147) were male and the remaining 41 per cent (103) were female. According to the level of education, 48 per cent (120) of participants were found to be at university level. Demographic summary of the participants is presented in Table 1.

Table I. Demographic Summary $(N=250)$

\begin{tabular}{lc}
\hline \multicolumn{1}{c}{ Variables } & Frequency $(\%)$ \\
\hline Gender & \\
Male & $147(58.8)$ \\
Female & $103(41.2)$ \\
& \\
Qualification & \\
High school & $5(2.0)$ \\
College graduate & $68(27.2)$ \\
University graduate & $120(48.0)$ \\
Postgraduate & $57(22.8)$ \\
& \\
Marital Status & \\
Single & $102(40.8)$ \\
Married & $148(59.2)$ \\
& \\
Age in Years & \\
Under 30 years & \\
$30 \sim 40$ years & $67(26.8)$ \\
$41 \sim 50$ years & $89(35.6)$ \\
50 years and above & $50(20.0)$ \\
Tenure & $44(17.6)$ \\
Under 3 years & \\
$3 \sim 5$ years & \\
5 years and above & $80(32.0)$ \\
& $118(47.2)$ \\
& $52(20.8)$ \\
\hline
\end{tabular}

\subsection{Measure}

The original survey was prepared in English, then the scales was translated into Vietnamese based on translation procedure of Brislin [39]. After asking 10 employees about item ambiguity, the final questionnaire were available for collecting data. The study constructs were operationalized using a multi-item scale consist of positive statements with a total of 31 items.

Trust. Trust was measured by the 10-item scale derived from Mayer et al. [40]. Examples of these items included: "My organization is genuine and sincere"; "My organization would keep its commitment". Government officers responded on the 5-point Likert scale ranging from 1 (strongly disagree) to 5 (strongly agree).

Team culture. A 5-point, four-item scale measuring team culture was adopted from Kelloway and Barling [41]. An example item is "I would feel comfortable walking up to anyone in my organization and starting a conversation". 
Knowledge Sharing. Respondents assessed knowledge sharing with nine items [41] on a 5-point Likert scale. Examples of these items included: "My organization is genuine and sincere"; "My organization would keep its commitment".

OCBs. OCBs were measured using a eight-item scale developed by Organ [26]. In this study, OCBs only refered to behaviors target to individuals [26]. An example item is "I am willing to help co-workers when they are absent".

\subsection{Data Analysis Method}

The current study was utilized the technique of partial least square - structural equation modeling (PLS-SEM) through using Smart-PLS software (version 3). This software employs the algorithm that regresses partial relationships by using separate ordinary least squares regression [42]. PLS-SEM is not restricted to normally distributed assumptions and applied to both large and small sample [43].

\subsection{Measurement Model}

Before analyzing structural model, the test of reliability and validity was conducted based on values of factor loadings, Cronbach's Alpha, composite reliability (CR), average variance extracted (AVE), and discriminant validity (DV). As shown in Table II, there are two items of trust scale and one item of knowledge sharing scale deleted because of lower loading value of 0.60 [44]. The value of Cronbach's alpha for all constructs are higher than 0.70 indicating good internal consistency and strong reliability [42]. The CR values of four constructs are above the acceptable threshold value of 0.70 as recommended by [42]. The reported AVE exceeded the recommended value of 0.50 by [42]. Finally, the computation of DV in Table III ranged from 0.245 to , lower than acceptable value of 0.85 by [42].

Table II. Construct reliability and validity

\begin{tabular}{lcccc}
\hline Variables & Loadings & Cronbach's Alpha & CR & AVE \\
\hline Trust & $0.873 \sim 0.887$ & 0.942 & 0.954 & 0.776 \\
Team Culture & $0.711 \sim 0.875$ & 0.828 & 0.883 & 0.654 \\
Knowledge Sharing & $0.737 \sim 0.840$ & 0.806 & 0.873 & 0.632 \\
OCBs & $0.882 \sim 0.887$ & 0.845 & 0.890 & 0.618 \\
\hline
\end{tabular}

Table III. Discriminant validity

\begin{tabular}{lcccc}
\hline & Trust & Team Culture & Knowledge Sharing & OCBs \\
\hline Trust & 0.795 & & & \\
Team Culture & 0.558 & 0.801 & & \\
Knowledge Sharing & 0.681 & 0.566 & 0.786 & 0.578 \\
OCBs & 0.467 & 0.245 & 0.809 \\
\hline
\end{tabular}

\section{RESULTS}

The bootstrap technique was conducted to analyze the significance of path coefficients. Table IV exhibited the results of hypothesis testing. Test of significance revealed that trust had strong influence on OCBs $(\beta=0.567 ; p<0.001)$ and knowledge sharing $(\beta=0.559 ; \mathrm{p}<0.001)$. Thus, $\mathrm{H} 1$ and $\mathrm{H} 2$ were supported. Moreover, the direct relationships of team culture toward to knowledge sharing $(\beta=0.171 ; p<0.001)$ and OCBs $(\beta=0.181 ; p<0.001)$ were found to be statistically significant. Hence, H3 and H4 were supported. In sum, the models explain the variance of 34.0 per cent for knowledge sharing and 35.2 per cent for OCBs, which met the requirements suggested by Hair et al. [42].

Table IV. Hypothesis testing

\begin{tabular}{lcccc}
\hline & $\begin{array}{c}\text { Path } \\
\text { coefficients }\end{array}$ & t- Statistics & p values & Accept/ Reject \\
\hline H1: Trust $\rightarrow$ Knowledge sharing & 0.559 & 12.698 & 0.000 & Accepted \\
H2: Trust $\rightarrow$ OCBs & 0.567 & 13.657 & 0.000 & Accepted \\
H3: Team culture $\rightarrow$ Knowledge sharing & 0.171 & 3.779 & 0.000 & Accepted \\
H4: Team culture $\rightarrow$ OCBs & 0.181 & 4.033 & 0.000 & Accepted \\
\hline
\end{tabular}




\section{DISCUSSION}

The current study discovers the influence of trust and team culture on knowledge sharing and OCBs. This research shows significantly positive relationship between trust toward knowledge sharing and OCBs, which are supported by previous findings (e.g. [4, 27]). Moreover, the results of this study supports findings of Jamshed and Majeed [37]'s study that conclude that team culture is positively related to knowledge sharing. In addition, team culture positively influence OCBs of government officials, which endorses the arguments of previous studies (e.g. [36]).

These findings also generate the framework of knowledge sharing and OCBs that are considered as voluntary behaviors, which can highly influence job performance (e.g., [45, 46]). Trust enables team members to reduce barriers in sharing knowledge, and encourage them to help co-workers voluntarily. Mutual trust among team members also contribute to readiness of voluntary behaviors. Morever, culture of team spreads and praise the voluntary behaviors (i.e., knowledge sharing and OCBs) based on members' recognition.

Managers can utilize practices that encourage trust and team culture among team members in order to enhance knowledge sharing and OCBs. In terms of trust, managers should empower team members and motivate them to devote to team responsibility. Also, managers should keep the promises and match words with actions. Diffuse regulations and shared rules can guarantee the trust and team culture. Morever, developing a helping environment among employees generates strong team culture that improve and enhance OCBs.

\section{Limitation and future recommendation}

First, the data collection was confined to respondents from government officials at Binh Dinh province. Future study should attempt to collect larger sample size in different cities and provinces in Vietnam, which might conduct a comparative research. Second, this study concentrates on the direct relationships between trust and team culture toward knowledge sharing and OCBs. Therefore, future research could analyze the mediating and moderating effects that can influence to these direct correlations. Finally, using cross-sectional time frame may influence to the results when time flies, thus, a longitudinal study may support to better understand the causal relationships.

\section{ACKNOLEDGMENT}

This work belongs to the project grant No: T2021-20. funded by Ho Chi Minh City University of Technology and Education, Vietnam

\section{REFERENCES}

[1] S. Hess, The government/press connection: Press officers and their offices, Brookings Institution Press, Washington, 2010.

[2] T. Luu, Knowledge Sharing in Public Organizations: The Roles of Servant Leadership and Organizational Citizenship Behavior, International Journal of Public Administration, 40 (4) (2017) 361-373.

[3] H. Yildiz, The interactive effect of positive psychological capital and organizational trust on organizational citizenship behavior, SAGE Open, 9 (3) (2019) 1-15.

[4] P. Pinjani, P. Palvia, Trust and knowledge sharing in diverse global virtual teams, Information \& Management, 50 (4) (2013) 144-153.

[5] D.Z. Levin, R. Cross, L.C. Abrams, E.L. Lesser, Trust and knowledge sharing: A critical combination, IBM Institute for Knowledge-based Organizations, 19 (10) (2002) 1-11.

[6] E. Ma, Y. Zhang, F.Z. Xu, D. Wang, M.S. Kim, Feeling empowered and doing good? A psychological mechanism of empowerment, self-esteem, perceived trust, and OCBs, Tourism Management, 87 (2021) 1-12.

[7] T.Y. Chen, S.N. Hwang, Y. Liu, Antecedents of the voluntary performance of employees: Clarifying the roles of employee satisfaction and trust, Public Personnel Management, 41 (3) (2012) 407-420. 
[8] H. Zeinabadi, K. Salehi, Role of procedural justice, trust, job satisfaction, and organizational commitment in Organizational Citizenship Behavior (OCB) of teachers: Proposing a modified social exchange model, ProcediaSocial and Behavioral Sciences, 29 (2011) 1472-1481.

[9] R. Cropanzano, M.S. Mitchell, Social exchange theory: An interdisciplinary review, Journal of Management, 31 (6) (2005) 874-900.

[10] X. Zhang, P.O. De Pablos, Q. Xu, Culture effects on the knowledge sharing in multi-national virtual classes: A mixed method, Computers in Human Behavior, 31 (2014) 491-498.

[11] T. Molose, I.O. Ezeuduji, Knowledge sharing, team culture, and service innovation in the hospitality sector: the case of South Africa, African Journal of Hospitality, Tourism and Leisure, 4 (1) (2015) 1-16.

[12] M.S. Arumi, N. Aldrin, T.R. Murti, Effect of organizational culture on organizational citizenship behavior with organizational commitment as a mediator, International Journal of Research in Business and Social Science, 8 (4) (2019) 124-132.

[13] F. Ahmed, K. Shahzad, H. Aslam, S.U. Bajwa, R. Bahoo, The role of collaborative culture in knowledge sharing and creativity among employees, Pakistan Journal of Commerce and Social Sciences, 10 (2) (2016) 335-358.

[14] J. Musso, C. Weare, M. Hale, Designing web technologies for local gover-nance reform: Good management or good democracy, Political Communication, 17 (1) (2000) 1-19.

[15] C. Tolbert, K. Mossberger, The effects of e-government on trust and confi-dence in government, Public Administration Review, 66 (3) (2006) 354-369.

[16] W. K. Daniel, Challenges on privacy and reliability in cloud computing security. Proceeding of the 2014 International Conference on Information Science, Electronics and Electrical Engineering, Sapporo, Japan, 2014, April.

[17] R.C. Nyhan, H.A. Marlowe Jr, Development and psychometric properties of the organizational trust inventory, Evaluation Review, 21 (5) (1997) 614-635.

[18] P. Palvia, The role of trust in e-commerce relational exchange: A unified model, Information \& Management, 46 (4) (2009) 213-220.

[19] J. Barbalet, Social Emotions: Confidence, Trust, and Loyalty, International Journal of Sociology and Social Policy, $16(9 / 10)(1996) 75-96$.

[20] J.D. Lewis, A.J. Weigert, The social dynamics of trust: Theoretical and empirical research, 1985-2012., Social Forces, 91 (1) (2012) 25-31.

[21] J.D. Lewis, A. Weigert, Trust as a social reality, Social Forces, 63 (4) (1985) 967-985.

[22] M.L. Hu, T.L. Ou, H.J. Chiou, L.C. Lin, Effects of social exchange and trust on knowledge sharing and service innovation, Social Behavior and Personality, 40 (5) (2012) 736-800.

[23] K.E. Sveiby, R. Simons, Collaborative climate and effectiveness of knowledge work-an empirical study, Journal of Knowledge Management, 6(5) (2002) 420-433.

[24] P. Garg, R. Rastogi, Climate profile and OCBs of teachers in public and private schools of India, International Journal of Educational Management, 20 (7) (2006) 529-541.

[25] P.M. Podsakoff, S.B. MacKenzie, J.B. Paine, D.G. Bachrach, Organizational citizenship behaviors: a critical review of the theoretical and empirical literature and suggestions for future research," Journal of Management, 26 (2000) 513 - 563.

[26] D. Organ, Organizational Citizenship Behavior: The Good Soldier Syndrome, Lexington Books, Lexington, 1988.

[27] E. Ma, H. Qu, M. Wilson, K. Eastman, Modeling OCB for hotels: Don’t forget the customers," Cornell Hospitality Quarterly, 54 (3) (2013) 308-317. 
[28] A. Cohen, E. Ben-Tura, D.R. Vashdi, The relationship between social exchange variables, OCB, and performance: what happens when you consider group characteristics?, Personnel Review, 41 (6) (2012) 705-731.

[29] M.A. Konovsky, S.D. Pugh, Citizenship behavior and social exchange, Academy of Management Journal, 37 (3) (1994) 656-669.

[30] R. McDermott, C. O’dell, Overcoming cultural barriers to sharing knowledge, Journal of Knowledge Management, 5 (1) (2001) 76-85.

[31] E. Schein, Organizational Culture and Leadership, Jossey-Bass, San Francisco, 1985.

[32] C.P. Earley, E. Mosakowski, Creating hybrid team cultures: An empirical test of transnational team functioning, Academy of Management Journal, 43 (1) (2000) 26-49.

[33] M.L. Hu, J.S. Horng, Y.H.C. Sun, Hospitality teams: Knowledge sharing and service innovation performance, Tourism Management, 30 (1) (2009) 41-50.

[34] J. Mueller, Knowledge sharing between project teams and its cultural antecedents, Journal of Knowledge Management, 16 (3) (2012) 435-447.

[35] D. Power, T. Schoenherr, D. Samson, The cultural characteristic of individualism/collectivism: A comparative study of implications for investment in operations between emerging Asian and industrialized Western countries, Journal of Operations Management, 28 (3) (2010) 206-222.

[36] J.Y. Lai, L.W. Lam, S.S. Lam, Organizational citizenship behavior in work groups: A team cultural perspective, Journal of Organizational Behavior, 34 (7) (2013) 1039-1056.

[37] S. Jamshed, N. Majeed, Relationship between team culture and team performance through lens of knowledge sharing and team emotional intelligence, Journal of Knowledge Management, 23 (1) (2019) 90-109.

[38] C.A. O’Reilly, J.A. Chatman, Culture as social control: Corporations, cults, and commitment, Research in Organizational Behavior, 18 (1996) 157-200.

[39] R. W. Brislin, Translation and content analysis of oral and written material, in: Handbook of cross-cultural psychology, Allyn \& Bacon, Boston, MA, 1980, pp. 349-444.

[40] R.C. Mayer, J.H. Davis, F.D. Schoormann, An integrative model of organizational trust, Academy of Management Review, 20 (3) (1995) 709-734.

[41] E.K. Kelloway, J. Barling, Knowledge work as organizational behavior, International Journal of Management Review, 2 (3) (2000) 287-304.

[42] J.F. Hair, J.J. Risher, M. Sarstedt, C.M. Ringle, When to use and how to report the results of PLS-SEM, European Business Review, 31 (1) (2019) 2-24.

[43] J.F. Hair, C.M. Ringle, M. Sarstedt, PLS-SEM: indeed a silver bullet, Journal of Marketing Theory and Practice, 19 (2) (2011) 139-152.

[44] J.F. Hair, M. Sarstedt, C.M. Ringle, J.A. Mena, An assessment of the use of partial least squares structural equation modeling in marketing research, Journal of the Academy of Marketing Science, 40 (3) (2012) 414-433.

[45] T.M. Nielsen, D.G. Bachrach, E. Sundstrom, T.R. Halfhill, Utility of OCB: Organizational citizenship behavior and group performance in a resource allocation framework, Journal of Management, 38 (2) (2012) 668-694.

[46] R. Du, S. Ai, Y. Ren, Relationship between knowledge sharing and performance: A survey in Xi'an, China, Expert systems with Applications, 32 (1) (2007) 38-46. 